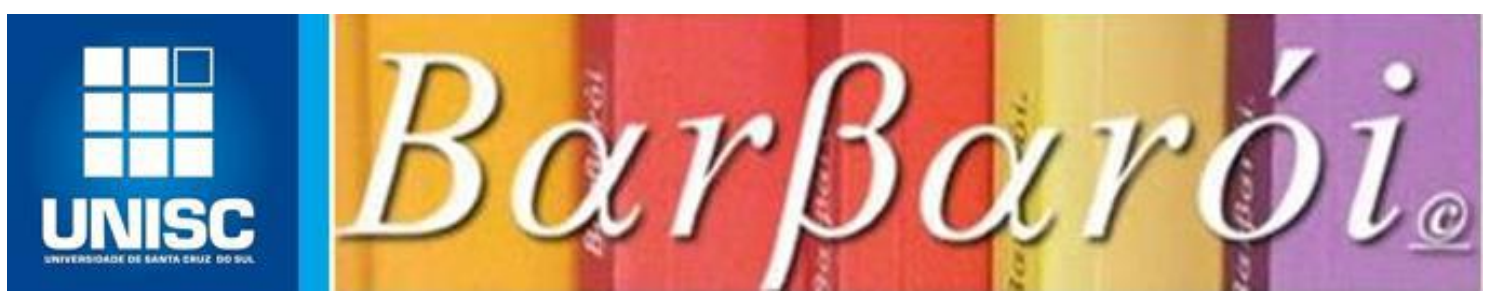

\title{
CAMINHOS DA IMAGINAÇÃO SOCIOLÓGICA OU DE COMO ME TORNEI UMA SOCIÓLOGA
}

DOI: http://dx.doi.org/10.17058/barbaroi.v0i0.14592

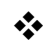 \\ Marília Patta Ramos \\ Universidade Federal do Rio Grande do Sul - UFRGS - Brasil
}

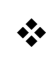

\section{Resumo}

O presente artigo trata-se de um ensaio, quase biográfico, sobre a trajetória de uma socióloga, em particular de uma profissional que iniciou sua vida profissional no departamento de Ciências Humanas da Universidade de Santa Cruz do Sul. O texto está estruturado em vários itens, mas a rigor segue uma organização cronológica que inicia com a descrição da origem social da autora, a sua escolha pelas Ciências Sociais, a qual a autora argumenta ter profunda relação com sua origem; a formação acadêmica em nível de graduação e pós-graduação, mestrado e doutorado e sua profissionalização desde quando ingressou na UNISC até os dias de hoje, como docente e pesquisadora na UFRGS. Se utilizando de forte influência weberiana e porque não dizer, bourdiesana, a autora conecta suas escolhas profissionais a sua origem social bem como com as opções com as quais se deparou naquele percurso. No artigo a autora reflete sobre o fazer sociológico de uma profissional com perfil pragmático e aplicado bem como traz uma descrição dos temas por ela pesquisados no seu percurso enquanto docente e pesquisadora.

Palavras-chave: Sociologia, escolhas profissionais, fazer sociológico, atuação acadêmica.

\section{Introdução}

Este ensaio apresenta a trajetória de uma socióloga latino-americana não muito convencional. ${ }^{1}$ Esta Socióloga sou eu, por isso vou me permitir escrever na primeira pessoa.

Ao longo do processo de organização deste ensaio percebi quão importante pode ser uma síntese retrospectiva, que acaba sendo, mesmo sem querer, uma reflexão sobre as opções feitas e uma avaliação sobre os resultados acerca das decisões tomadas. É curioso, mas a história da vida profissional acaba sendo parte integrante de algo mais amplo, podendo ser entendido como "fazerse", tal como descreveu Thompson (1987), "um processo ativo, que se deve tanto à ação humana como aos condicionantes".

\footnotetext{
${ }^{1}$ No decorrer do ensaio o leitor vai entender porque me considero uma socióloga não convencional. Barbarói, Santa Cruz do Sul, Edição Especial n.54, p.<47-62>, jul./dez. 2019
} 
Ao refletir e descrever sobre o que fiz, percebi que minhas ações e decisões estavam sempre imersas em contextos, em situações, muitas das quais não criadas por mim e tampouco sob meu controle. Mas a todo momento percebi um traço central de minha personalidade, que também é uma das minhas crenças como cientista social, que reside na capacidade de agência da qual todos somos dotados. Me socorro em um dos autores centrais que orienta minha compreensão sociológica. Norman Long (2007) define a capacidade de agência como aquela que "atribui ao ator individual a capacidade de processar a experiência social e desenhar maneiras de lidar com a vida, ainda que sob as formas mais extremas de coerção. Nos limites da informação, incerteza e outras restrições (físicas, normativas ou político-econômicas), os atores sociais possuem capacidade de saber e capacidade de atuar" (Long, 2007, p. 48).

Meu contato com a sociologia é algo difuso e misterioso até hoje, devo confessar. Creio que a lembrança mais remota que tenho me leva a memória sobre algum talento relacionado ao humanismo e ao pensamento social ainda no ensino básico nas famigeradas aulas de OSPB, onde se estudava o Estado, sua estrutura e funções. Mas em realidade, ter crescido nua casa cheia de livros, muito deles de filosofia, psicanálise e história deve ter tido sim grande impacto nas minhas escolhas. Meu pai, ainda que tenha sido um profissional da área da saúde, sempre foi um apreciador da história do pensamento social mundial, comprava e lia livros de psicanálise e comportamento humano, todos eles sempre ao meu alcance numa enorme estante estilo clássico-sóbrio, herdada de um tio médico, que ele ainda conserva em sua residência na minha terra Natal: Cachoeira do Sul.

Este texto está estruturado em vários itens, mas a rigor segue uma organização cronológica que inicia com a descrição de minha origem social, minha escolha pelas Ciências Sociais, a qual creio eu tem profunda relação com minha origem a formação acadêmica em nível de graduação e pós-graduação, mestrado e doutorado e minha profissionalização desde quando entrei na UNISC até os dias de hoje, como docente e pesquisadora na UFRGS.

\section{Trajetória e percurso de uma escolha: Weber e a questão da objetividade nas Ciências Sociais}

Weber (1991) nos diz que a objetividade na ciência só é possível após a escolha do que queremos estudar. Minha opção pelo curso de Ciências Sociais (não havia e não há curso de graduação em de Sociologia na UFRGS) pareceu algo inusitado para meu maior incentivador e apoiador: meu pai. Um dia em outubro de 1985 tomei um ônibus da minha cidade Natal para Porto Alegre para ir me inscrever no vestibular, já que naqueles tempos 
nada era "online". O curso que eu deveria me inscrever, dados meus interesses deveria ser Farmácia, mas no trajeto pensei muito e chegando em POA me inscrevi para Ciências Sociais. No retorno para casa contei ao meu pai, que sem me julgar me indagou: "ah então queres ser professora?” e eu disse: “não, quero ser uma cientista social”. Naquela época eu não tinha a mínima noção que minha escolha estava permeada por uma trajetória de vida envolta em duas classes sociais: meu pai de origem latifundiária e minha mãe de origem popular de baixo status socioeconômico, mas com um habitus de classe muito próximo da burguesia por ter tias professoras.

Assim, vivi minha vida toda entre dois mundos, ainda que minha mãe tivesse um background educacional razoável, sua classe econômica sempre contrastou com a de meu pai. Assim sendo, a neutralidade na escolha de meu curso de graduação seria uma falácia posto que estava envolta a uma vida recheada de contrastes de classe, os quais me instigavam a querer compreendê-los ainda que tomada, muitas vezes, de certa indignação e vontade de romper com as injustiças sociais. Tais contrastes vão ser a mola propulsora de minhas escolhas quanto às temáticas de pesquisa que escolhi durante minha trajetória enquanto cientista do social.

\section{A formação: o sonho de ser cientista frente à militância}

\section{A graduação}

Terminei o ensino médio ao final da década de 80 , quando a economia brasileira entrara em recessão e a instabilidade crescia em velocidade galopante. Houve vários planos econômicos (Verão, Cruzado, Bresser, etc), a moeda nacional perdia seu valor e a toda hora se cortavam alguns zeros, tal era a instabilidade política do governo Sarney, o que fez com ao final daquela derradeira "década perdida".

Sair de uma cidade do interior e passar a viver numa capital não foi fácil, estava acostumada a andar a pé para percorrer as curtas distâncias entre a escola, casa e o centro da cidade. Já em POA tive de aprender a andar de ônibus e a usar muito as fichinhas para poder me comunicar com a família e amigos via telefones públicos (os “orelhões), já que possuir uma linha telefônica era algo para os mais afortunados. Não posso dizer que minha condição familiar privilegiada de classe não tenha favorecido bastante minha vida em Porto Alegre, morava num apartamento da família e não precisava me preocupar com as contas da casa, vivia sob um confortável "paitrocínio".

Adentrar no mundo de uma Universidade Pública aos 17 anos recém feitos foi um choque, ainda mais num curso de Humanas, onde a maioria dos alunos era mais velha que eu, Barbarói, Santa Cruz do Sul, Edição Especial n.54, p.<47-62>,jul./dez. 2019 
já trabalhava e fazia algo que eu não estava acostumada: militava em partidos políticos e/ou movimentos sociais. Conheci o mundo da militância antes mesmo da primeira eleição direta para presidente da República, que foi em 1989 quando eu já estava no último ano da graduação. Confesso que me parecia muito complicado a ideia Gramsciana de um intelectual orgânico, envolto nas causas sociais.

Já nos primeiro anos do curso, me dedicava muito às leituras, não deixava de ler nada que era solicitado, até participava de algumas reuniões do CECS (Centro de estudantes de Ciências Sociais), mas não conseguia dividir meu tempo de forma a dar conta dos trabalhos, resenhas, algumas provas, palestras e congressos que me instigavam a pensar no mundo sob ponto de vista agora muito diferente do senso comum, mas que me abriram as portas para, de acordo com Weber, compreender minha origem social, a qual sempre me instigou a querer estudar a sociedade e quiçá mudar tudo aquilo que eu achava injusto. Obviamente que Karl Marx me fez, não só nominar, mas entender que o problema das diferenças de classe era o que me motivava a querer ser uma Cientista do Social.

Vivi um tempo certo conflito, o que foi muito proveitoso, entre o que a maioria de meus colegas mais gostava e fazia, a militância política e minha formação para ser uma cientista social.

Confesso que me sentia uma outsider pois não me encaixava ne com um grupo mais contestador/revolucionário nos costumes e nem com os militantes, politizados, engajados em movimentos sociais e/ou associações/sindicatos. Eu ficava no meio, dividida, mas noutro canto: no lugar da Ciência, de conhecimento queria adquirir não só para ser uma intelectual e reproduzir os clássicos com propriedade. Eu sempre quis me debruçar sobre um conhecimento mais aplicado, mais "útil” de forma imediata.

Assim sendo, me envolvi em dois estágios extracurriculares. O primeiro foi na SMOV (Secretaria Municipal de Obras e Viação) da prefeitura de Porto Alegre onde eu saía com um grupo de estagiários da área de arquitetura para fazer levantamento físico das moradias de sub-habitação em favelas da zona Norte de POA. No começo custei a me acostumar com cheiro das ruas com esgoto a céu aberto, mas depois pude aproveitar aquele conhecimento empírico para pensar a desigualdade para além dos livros de Sociologia. Foi um aprendizado tanto metodológico, pois tínhamos de produzir relatórios descritivos, com tabelas e gráficos (antes do advento os PCs), quanto prático.

Meu segundo estágio foi na Fundação de Economia e Estatística (a hoje extinta FEE) onde fiz um trabalho menos aplicado e mais científico junto com uma pesquisadora economista na área de estudos agrários. Aí o destino me colocou diante de uma temática que, Barbarói, Santa Cruz do Sul, Edição Especial n.54, p.<47-62>, jul./dez. 2019 
de certa forma, fazia parte de minhas origens: o mundo rural, minha família por de origem latifundiária, as questões rurais sempre estiveram presentes na minha vida. Na FEE pude começar a conhecer mais a pesquisa aplicada e a conviver com economistas, demógrafos e a ter como chefe maior, a presidente da FEE na época e nossa ex presidenta Dilma Russef.

Como estava no último ano da graduação em Ciências Sociais comecei a cogitar a possibilidade de postergar a formatura para continuar o estágio remunerado na FEE e assim fiz. Me formei no bacharelado e continuei na licenciatura, o que me trouxe duas cerimônias de formatura, uma no início e outra no final de 1990. Por influência de minha supervisora na FEE, onde eu pude submergir no mundo da pesquisa científica aplicada, envolta em dados censitários, gráficos e tabelas (tudo no papel, pois não havia nada digitalizado e a internet ainda não era uma realidade), comecei a cogitar fazer seleção para o Mestrado em Sociologia Rural na UFRGS e assim fiz em fins do ano de 1990.

\section{A opção pela Pós Graduação}

Em 1991, com 22 anos, eu adentrava no Mestrado em Sociologia Rural da UFRGS. $\mathrm{Na}$ época eu atribua minha escolha à influência de minha supervisora na FEE, mas depois me dei conta daquilo que mencionei no começo deste ensaio: nossas escolhas nunca são neutras ou meramente geradas por uma influência imediata de uma pessoa. Ter entrado na Sociologia Rural e lá ter feito uma dissertação sobre as Estratégias de Reprodução Social da Burguesia Agrária no RS tinha profunda ligação com minhas origens, em específico com a origem latifundiária de minha família paterna.

E assim segui, por 3 anos com bolsa da Capes, vivendo intensamente as leituras sobre o meio rural, as discussões sobre o campesinato, os latifundiários, a produção rural, o papel do Estado, os movimentos sociais e os conflitos no espaço agrário. Pude conhecer um pouco dos meandros do Movimento Sem Terra, com algumas saídas de campo para acampamentos (Annoni e Ronda Alta) e trabalhando como voluntária no setor de arquivo e documentação na sede daquele movimento em Porto Alegre, por um período de um ano e meio.

\section{A profissionalização: CVs na caixa de Correio e o primeiro emprego}

No final do terceiro ano do Mestrado (naquele época o Mestrado durava 3 anos) já pensando no que fazer quando a bolsa acabasse, decidi imprimir na minha impressora matricial 12 cópias de meu Curriculum vitae e enviar pelo correio para faculdades particulares do Rio Grande do Sul. Das 12 apenas uma me chamou: numa sexta feita de Março de 1993 recebi um telefonema do chefe do departamento de Ciências Humanas das Faculdades Barbarói, Santa Cruz do Sul, Edição Especial n.54, p.<47-62>, jul./dez. 2019 
Integradas de Santa Cruz do Sul, me convidando para substituir de forma emergencial, por contrato de horista, uma professora que os tinha deixado de última hora. Viajei para lá no mesmo dia e logo acertamos as disciplinas que eu ministraria, por um contrato temporário até Julho de 1993.

Em meados de Março de 1993, eu com apenas 24 anos adentrava numa sala de aula, sem qualquer experiência anterior de sala de aula, no curso noturno de Estudos Sociais, para ministrar Metodologia da Pesquisa Científica. O nervosismo foi grande, suava nas mãos, mas não me abati diante de uma turma onde a maioria das pessoas era muito mais velha do que eu. Logo me vi desenvolta com as lâminas (os equipamentos de projeção multimídia ainda não eram uma realidade) e manejando o retroprojetor com familiaridade.

Em junho de 1993 a FISC passou a ser reconhecida como universidade e passou a se chamar UNISC (Universidade de Santa Cruz do Sul), sendo considerada uma universidade pública não estatal, por ter como dono não uma pessoa, mas uma associação da comunidade (APESC) que reinveste na instituição o que arrecada com as mensalidades, sendo parte da rede de universidades comunitárias gaúchas. Fiquei muito feliz e mais ainda quando surgiu a possibilidade de eu fazer concurso e ser efetivada como horista. Assim, em Julho de 1993 fiz o concurso para disciplina de Metodologia e fui aprovada. Ainda não era um cargo muito garantido porque eu dependia da oferta de disciplinas para estar atuando, era docente-horista somente, não tinha vinculo de pesquisa ainda. Naquele período continuei a residir em Porto Alegre e viajava para Santa Cruz do Sul nas noites que tinha de lecionar, a UNISC nos pagava além da hora aula, hotel e passagem de ônibus, conheci muitos colegas na mesma situação e fiz amizades que duram até os dias de hoje.

Atuei no ano de 1993 como horista e em 1994 fui promovida para 20hs onde comecei minhas atividades como pesquisadora na UNISC. Em 1996, já tendo me tornado mãe no ano anterior, fui promovida para 40hs, tendo aí me mudado para a cidade de Santa Cruz do Sul, mas entre 1994 e 1996, mesmo tendo apenas 20hs pude adentrar no mundo da pesquisa aplicada.

\section{A pesquisa social Aplicada numa Universidade Comunitária: descendo do Céu a Terra}

Sendo a UNISC uma universidade de caráter comunitário suas atividades de pesquisa estão muito atreladas às demandas da comunidade onde está inserida. Um dos primeiros trabalhos que fiz, já como pesquisadora, foram dois Censos Sócio demográficos para duas prefeituras de municípios recém criados, mediante a emancipação de dois distritos de Santa Cruz do Sul: Gramado Xavier e Vale do Sol. Pude participar, junto com mais dois colegas sociólogos do departamento de Ciências Humanas, da produção do questionário, do Barbarói, Santa Cruz do Sul, Edição Especial n.54, p.<47-62>, jul./dez. 2019 
treinamento dos recenseadores e da posterior análise dos dados e produção do relatório final. Mas, nosso trabalho também inclua inúmeras saídas de campo, para supervisionar e às vezes até aplicar os questionários.

Foi uma experiência muito interessante, participar de todas as etapas de uma pesquisa aplicada e junto com a comunidade debater sobre as necessidades daqueles dois novos municípios e pensar, junto com os gestores públicos, ações concretas relacionadas com as primeiras políticas públicas para aquelas localidades.

\section{Das Pesquisas Eleitorais: como fazer pesquisa quando a ideologia política te desafia}

As pesquisas das quais participava se vinculavam ao Gabinete de Investigação Social, o GIS, do departamento de Ciências Humanas da UNISC, o qual mudou de nome e passou a se chamar, até hoje, Núcleo de Pesquisa Social. Em fins de 1994 e início de 1995 a coordenadora daquele núcleo saiu da UNISC para assumir como professora numa universidade federal noutro estado Brasileiro e eu assumi a coordenação do NUPES. Passei a fazer o que a maioria dos sociólogos, ao menos naquela época, nem considerava como sendo um "fazer sociológico", qual seja: fazer pesquisas sociais aplicadas por encomenda. Não me abatia diante das críticas e seguia firme, por tentativa erro, em querer aprender um pouco de pesquisa quantitativa para responder às demandas pontuais da comunidade.

Especificamente o grande desafio, em termos de aprendizagem e paciência, posso dizer, foram as "famigeradas" pesquisas eleitorais, demandadas pelo Jornal local e por alguns partidos políticos da região do Vale do Rio Pardo. Com elas pude aprender, não só sobre política partidária, mas muito sobre construção de amostra, margem de erro, nível de confiança, elaboração de surveys, digitação de dados e análises no SPSS (Statistical Package for the Social Science).

Posso dizer que fazer pesquisas eleitorais era quase uma aventura por terrenos “inóspitos", onde tinha de mostrar minha capacidade não só como pesquisadora mas também como membro de uma instituição comunitária que era capaz de se abster de suas preferências e ter como demandantes/interlocutores pessoas muito diferentes quanto à minha opção político-ideológica. Aquela experiência me ensinou muito sobre o "mundo da pesquisa social aplicada" com todas as suas facetas, com elas iniciei o gosto pela estatística, pela quantificação na análise do mundo social, o que em muito influenciou minha opção, em fins de 1996, por aplicar para um doutorado numa universidade norte-americana, fugindo da tendência quase generalizada, reinante entre meus pares sociólogos por optarem por doutoramentos em universidades Europeias.

Barbarói, Santa Cruz do Sul, Edição Especial n.54, p.<47-62>,jul./dez. 2019 
Em Agosto de 1995 viajei aos EUA, pela primeira vez, para apresentar trabalho num congresso científico em Washington-DC e já visitar algumas Universidades onde eu almejava fazer meu doutorado. Visitei três instituições, em Ohio, Indiana e Wisconsin. Apliquei para Ohio e Indiana, e fui aceita em ambas, porém sem bolsa.

Em meados de 1996 apliquei para bolsa de doutorado integral na Capes e Cnpq e solicitei afastamento, com remuneração, da UNISC, a qual prontamente concedeu, pois na época era interesse daquele instituição aumentar o número de professores doutores. A Capes me concedeu bolsa de tipo II, isto é, somente pagamento de taxas e mensalidades, assim sendo optei pela Universidade de Purdue, em Indiana, EUA, por ter a taxas mais baratas. Como o dólar naquela época estava quase 1,22 Reais não foi difícil me manter com o salário da UNISC convertido em dólares.

\section{Conhecendo a Sociologia no Hemisfério Norte}

A chegada nos EUA, com esposo e filha com dois anos de idade, não foi nada fácil. Era Janeiro e a neve tomava conta das ruas e deixava os dias cinzentos e silenciosos. No início eu me deslumbrava com tudo, tudo era novidade, mas logo os desafios acadêmicos e da vida cotidiana se tornavam menos um deslumbramento e muito mais um constante cansaço misturado com a sensação de que eu não daria conta. Ainda por cima eu tinha de aprovar no TOEFL naquele semestre para ter o aceite definitivo da universidade, coisa que consegui na primeira prova que fiz, ainda em Janeiro logo que havia chegado. O dia inteiro imersa na língua, ouvindo e falando, logo me fizeram desbloquear e imediatamente passei na prova na qual havia reprovado três vezes aqui no Brasil.

Em duas semanas de minha chegada eu já encarava a sala de aula do $\mathrm{PhD}$ em Sociologia da Universidade de Purdue. As primeiras aulas eram de métodos quantitativos e teoria sociológica contemporânea, posto que consegui aproveitamento da teoria clássica realizada no meu Mestrado na UFRGS, não precisei cursá-la no doutorado.

No primeiro semestre (Janeiro até Maio de 1997) optei por fazer apenas 2 disciplinas e deixei a terceira para fazer como curso de verão em Junho daquele ano. As primeira aulas de métodos quantitativos foram um choque, não só pela questão da língua, mas porque eu não tinha praticamente nenhuma familiaridade com o assunto. Cabe lembrar que, em geral, os cursos de Ciências Sociais, e de Sociologia em específico, no Brasil não tratam quase nada sobre estatística e quantificação. Cabe aqui tecer um breve comentário sobre a carência do ensino de métodos quantitativos nas Ciências Sociais Brasileiras, seguindo a ideia de Cano (2012), para quem:

Barbarói, Santa Cruz do Sul, Edição Especial n.54, p.<47-62>, jul./dez. 2019 
[...] as ciências sociais brasileiras privilegiam a teoria em detrimento da pesquisa, promovendo um conhecimento antes erudito do que técnico. Em muitas universidades, os departamentos de ciências sociais ainda estão atrelados a Centros de Filosofia ou de Letras, frisando a origem comum desses saberes e distanciando as ciências sociais de conteúdos considerados mais técnicos, como a economia, apesar de esta última poder ser considerada, plenamente, uma ciência social (CANO, 2012, p.112).

Assim meu primeiro semestre no doutoramento em Sociologia numa universidade norte-americana me gerou muitos desafios, principalmente metodológicos. Porém, no segundo semestre eu já estava muito mais familiarizada e sabia que aqueles conhecimentos, os quais às vezes iam muito fundo na modelação matemática, seriam muito úteis para a minha formação. Estava já bem mais confortável com modelos econométricos complexos, os quais me encantavam (e me encantavam até hoje) na sua capacidade de reduzir fenômenos complexos em relações de causa efeito, e são muito úteis para a compreensão dos condicionantes de certos fenômenos sociais, de maneira ampla ,com alta validade externa, isto é, alta capacidade de generalização pelo grande número de dados que pode utilizar, ainda que sempre de forma aproximada e probabilística e parcialmente objetiva (todo e qualquer modelo econométrico é fruto de opções teóricas, de visões de mundo e maneiras específicas de operacionalizar as variáveis).

Com relação à temática que escolhi para minha tese, as relações sociais dos idosos e seu impacto na Depressão, novamente não foi uma escolha descolada de meu contexto pessoal. Certamente foi influenciado por eu ser filha de pais idosos e perceber que a população Brasileira estava envelhecendo a passos largos. Inclusive especificamente, na data de hoje, neste momento em que escrevo este ensaio o Estado do Rio Grande do Sul, onde nasci e onde atuo profissionalmente passa a ter uma população idosa (60 anos ou mais) que ultrapassa a população de crianças e adolescentes de zero até14 anos. Mais uma vez vemos que nossas escolhas temáticas não são neutras e estão sempre profundamente imbricadas nos contextos e vivencias presentes em nossas trajetórias.

Em Junho de 2001 eu defendi minha tese de doutorado e retornei definitivamente ao Brasil, após 4 anos e meio no processo de doutoramento.

\section{O retorno: a volta nem sempre é tão mais fácil}

O retorno ao Brasil e para a Unisc não foi um processo simples e livre de conflitos, ainda que estivesse muito animada com a possibilidade de aplicar os conhecimentos adquiridos no doutorado e logo iniciar minha atuação na pós-graduação lato sensu. Em termos, vamos dizer assim pedagógicos, tentei transpor certas práticas tais como provas mais 
frequentes, avaliações semanais (estilo tema de casa) e uma certa cobrança quanto à participação doa alunos. Confesso que não esperava tanta resistência, principalmente por parte de alunos da pós-graduação lato sensu. Tive de repensar e adaptar aquilo que eu gostaria de implementar com o que era possível aceitável para o contexto e expectativas dos alunos.

Logo retomei minhas atividades no NUPES como coordenadora novamente, atuei no grupo da UNISC sobre e para o envelhecimento saudável, o TIU (Terceira Idade na Universidade). Em um ano, após a espera da revalidação do diploma norte-americano, passei atuar num programa de pós-graduação stricto sensu, como professora, orientadora e pesquisadora no Programa de Pós Graduação em Desenvolvimento Regional, onde pude orientar vários alunos, fazer parte de grupos de pesquisa na área de desenvolvimento regional, coordenar a oficina de estatística daquele PPG e ministrar disciplinas de metodologia e métodos quantitativos. Em 2005 foi promovida, via análise da minha produção, a professora titular da UNISC.

\section{De volta ao solo "gringo" e a virada temática: o Mundo das Políticas Públicas}

Passados 4 anos de meu retorno do doutorado senti necessidade de me aperfeiçoar novamente e em 2005 apliquei para um programa da Capes de bolsas para Brasileiros estudarem métodos quantitativos e avaliação de Políticas Públicas na Universidade do Texas em Austin, EUA. Havia 5 bolsas por ano, naquele programa chamado Programa Vilmar Faria para Avaliação Quantitativa de Políticas Públicas ${ }^{2}$, destinadas a cientistas sociais Brasileiros, em fase de doutorado sanduíche ou pós doutoramento (meu caso). As bolsas envolviam passagem de ida e volta, seguro saúde, auxílio instalação e um valor mensal de por mês. Naquele ano de 2005 apenas eu e mais duas pessoas se inscreveram, fomos no que seria o último ano do referido programa, o qual foi extinto por falta de interessados.

Aquele ano que passei na Universidade do Texas (2006) na cidade de Austin pude dar uma guinada no meu tema de interesse, o qual passou a ser a avaliação de Impacto de Políticas Públicas. Diferentemente de outros pós-doutorados eu tive de cursar 6 disciplinas sobre avaliação e modelos econométricos de avaliação e impacto de intervenções governamentais. Aproveitei ao máximo aquele ano, sendo aluna novamente, mas sem a pressão de ter de produzir uma tese, me emaranhei num mundo muito novo, numa temática e em técnicas estatísticas as quais eu nunca havia tido contato antes. Foi desafiador e me trouxe

\footnotetext{
${ }^{2}$ Tal programa leva o nome de um sociólogo muito amigo do ex presidente e sociólogo Fernando Henrique Cardoso. Aquele sociólogo havia se dado conta da carência de profissionais na área de Ciências Sociais que dominassem métodos quantitativos, assim criou o programa em 2002, no governo FHC e que levou seu nome após sua morte.
}

Barbarói, Santa Cruz do Sul, Edição Especial n.54, p.<47-62>,jul./dez. 2019 
um capital que poucos sociólogos tinham no Brasil naquela época: conhecimento sobre técnicas estatísticas de avaliação de impacto. Este campo sempre foi e ainda é, posso dizer, restrito aos economistas e demógrafos.

Ao retornar ao Brasil em começo de 2007, além da grata surpresa de que, após 12 anos, seria mãe novamente, trouxe um conhecimento relativamente novo no campo das Políticas Públicas no Brasil. Assim logo fui contatada pelo governo do Estado do Rio Grande do Sul para ministrar um mini curso para os novos técnicos da Fundação de Economia e Estatística (FEE) sobre o tema da avaliação de impacto de Politicas Públicas bem como participar de uma consultoria junto a Secretaria de Saúde do Estado do RS. Assim eu começava no meu novo campo de pesquisa como uma socióloga mais aplicada: as Políticas Públicas.

Paralelamente eu passava a me inteirar sobre os grupos e eventos na área, passei a fazer parte da Rede Brasileira de Monitoramento e Avaliação, apresentei trabalho na Associação Brasileira de Estudos Populacionais e comecei meu contato com o campo que seria aquele em que atuo até hoje.

Ao mesmo tempo começavam a surgir no Brasil cursos de graduação e de pósgraduação na área de Políticas Públicas, Gestão Pública e Administração Pública. Paralelo a este novo cenário o governo federal da época lançou o Programa de Apoio a Planos de Reestruturação e Expansão das Universidades Federais (Reuni). Com ele houve a criação de 180 novos cursos de graduação. Para garantir a qualidade e o funcionamento dos cursos criados no âmbito do Reuni, as universidades tiveram condições de contratar novos docentes e técnicos administrativos. Na esteira daquela nova realidade a UFRGS criou em 2009 um novo curso, Bacharelado em Políticas Públicas para o qual abriu naquele ano um edital para concurso de 2 novos docentes específico para a nova área.

Ao me deparar com a aquela oportunidade, acabei decidindo fazer o concurso sem maiores pretensões e passei em primeiro lugar. Foi um pouco difícil minha decisão, mas optei por sair da UNISC após 17 anos vinculada àquela instituição que foi extremamente importante na minha trajetória.

\section{A decisão de voltar às origens: quando recomeçar pode valer a pena}

O início na UFRGS foi um tanto quanto estranho, tive de recomeçar minha carreira, pois na UNISC eu já era titular e na UFRGS comecei como adjunta 1. Tive de me adaptar ao contexto de uma universidade pública, a qual eu conhecia bem, mas como aluna. Como docente tudo era novidade, inclusive o curso para qual foi alocada para atuar.

Barbarói, Santa Cruz do Sul, Edição Especial n.54, p.<47-62>, jul./dez. 2019 
No ano de 2010 assumi disciplinas da graduação no novo curso de Políticas Públicas e no curso de Ciências Sociais, cursos estes que estão alocados no departamento de Sociologia da UFRGS. Somente no ano seguinte, 2011, entrei no PPG em Sociologia, onde ministrei e ministro disciplinas obrigatórias na área de metodologia da pesquisa além de orientar alunos e ter cargos administrativos (de 2011 até hoje já fui vice-coordenadora e integrante de comissões, das quais sou até os dias atuais). Pude vivenciar a passagem daquele PPG de um curso 5 para um curso stricto sensu de excelência, de nota 7 (nota máxima na Capes), junto com apenas outros 2 no Brasil inteiro. Experimentei momentos áureos daquele PPG quando havia muitos recursos financeiros para os PPGs em geral no Brasil e especificamente para os cursos de excelência uma gama de bolsas e auxílios para docentes e pesquisadores.

Em 2011 também consegui a tão disputada bolsa Produtividade (Pq) do Cnpq, a qual eu já havia por 3 anos consecutivos tentado sem sucesso. Meu projeto, pasmem, foi um projeto na área de avaliação de impacto de uma política pública, tema este nem sempre considerado como sendo um tema sociológico pelo mainstream da sociologia no Brasil, justamente por ser mais aplicado.

Além do recurso mensal financeiro esta bolsa PQ ajuda na obtenção de recursos para apresentação de trabalhos em congressos no Brasil e exterior. Assim sendo de 2011 para cá pude apresentar trabalhos e trocar experiências em congressos na área de Sociologia, com ênfase em Políticas Públicas, linha a qual me vinculo naquele PPG, em diversos contextos tais como: Chile, Áustria, Japão, Canadá, Argentina, EUA e neste ano será o Peru.

Dentre os projetos que já desenvolvi com a bolsa PQ posso mencionar 2 já concluídos e outro em conclusão ${ }^{3}$. O primeiro deles foi um estudo de avaliação de uma política pública centrada num programa na área da saúde do governo do Estado do Rio Grande do Sul especificamente fiz uma avaliação de Impacto do Programa Inverno Gaúcho da secretaria da Saúde do Estado do RS, a qual havia sido iniciada com aquela consultoria que prestei ao governo entre 2007 e 2009. No segundo período de bolsa PQ desenvolvi um estudo de avaliação de impacto do capital cultural no desempenho dos universitários Brasileiros. E finalmente no terceiro período de bolsa PQ que finda neste ano pude investigar o impacto do Programa Proinfância no provimento de pré-escolas no Estado do Rio Grande do Sul.

Em 2015 iniciou na UFRGS o PPG em Politicas Públicas, onde atuo desde sua fundação. Cabe destacar que cada vez mais minha atuação vai se consolidando naquele PPG

\footnotetext{
${ }^{3}$ Cada período de bolsa dura 3 anos e precisa ser renovado via encaminhamento de novo projeto ao CNPq ao final do terceiro ano
}

Barbarói, Santa Cruz do Sul, Edição Especial n.54, p.<47-62>,jul./dez. 2019 
como sendo o terreno onde transito de forma mais confortável e onde tenho a grande maioria de meus orientandos.

Cada vez mais me afasto das pesquisas menos pragmáticas e me aproximo mais de projetos de pesquisa mais aplicados, alguns vinculados a ações de extensão tais como cursos EAD e presenciais de avaliação de impacto oferecidos pela UFRGS, via Centro de Estudos Internacionais de Governo (CEGOV), onde também tenho vínculo, para gestores públicos do Brasil todo. Naquela linha participei de cursos para formação de gestores na área social, via antigo Ministério do Desenvolvimento Social e também para a Secretaria do Planejamento da Bahia. Além disse pude participar de pesquisas diagnósticas sobre Programas Sociais tais como o RS Mais Igual em 2015, onde atuei como uma das coordenadoras da parte quantitativa e também de uma pesquisa avaliativa sobre a Rede Escola de Governo do Estado do Rio Grande do Sul.

Minha atuação no CEGOV, a qual iniciou em 2014 e dura até hoje, me permitiu uma dedicação ainda maior no universo da avaliação de Politicas Públicas área esta cuja meta é poder informar à sociedade e aos governantes sobre o que funciona e o que não funciona em relação às intervenções estatais, sempre baseado em evidências. Para isso aquele conhecimento adquirido durante meu pós-doutoramento em 2006 na Universidade do Texas, via Programa Vilmar Faria, foi de extrema utilidade.

Cabe enfatizar que o Fazer Sociológico a que me dediquei nestes anos todos como docente e pesquisadora levou em conta o que nos diz Mills (1975) sobre a tarefa primeira da Sociologia em estabelecer a conexão de vida do cotidiano de indivíduos com os seus problemas sociais. Para aquele autor o sociólogo deve desenvolver um pensamento que estabelece conexões mais amplas entre indivíduo e sua sociedade. E para adquirir esta forma de visão é necessário analisar a sociedade onde vive de uma maneira externa, procurando minimizar a sua própria influência na análise uma vez que somos sempre carregados de valores culturais obtidos ao longo de sua vida. O sociólogo, para Mills, deve olhar para as coisas de maneira diferente da que está habituado na vida cotidiana.

\section{Considerações finais}

Como grande apreciadora do método comparativo, que Durkheim (1984) julgou ser o método sociológico por excelência, aprendi ao longo de minha formação como socióloga que só é valido dar-se crédito a um fato caso ele seja recorrente e seja constante ao longo do tempo. Ao longo destes 27 anos de trajetória acadêmica docente e de produção intelectual, 
procurei me ocupar com questões de pesquisa que eram consideradas relevantes na área aplicada e também enquanto demanda social.

Chega o momento de fazer uma avaliação sobre a trajetória percorrida e, a partir dela, lançar olhares sobre o futuro. Nesta trajetória a Universidade de Santa Cruz do Sul, através do departamento de Ciências Humanas e do NUPES, em específico, foi peça chave na minha formação, foi ela que me financiou boa parte de meu doutoramento, me possibilitando ficar 4 anos em licença remunerada, me proporcionou sempre condições de trabalho excelentes e me fez conhecer profundamente o mundo da pesquisa social aplicada, sem o qual eu certamente teria tido muito mais dificuldade em me especializar nos métodos quantitativos e ser hoje, vamos dizer assim, uma Socióloga do mundo real, das questões concretas da sociedade como um todo e das políticas públicas em particular. Certamente a formação norte-americana contribuiu sobremaneira para isso, mas foi a UNISC, junto com a CAPES, que tornou viável a minha formação.

Com relação ao contexto universitário atual, tenho a percepção que Universidade brasileira está passando por mudanças, sobre os quais me parecem faltar reflexões. Estão se consolidando novos modos de produzir conhecimento e fazer ciência. A produção científica está deixando de ser realizada de modo individual e cada vez mais passa a ser feita em grupos e por meio de redes, seja na forma de projetos de equipe ou outros mecanismos.

Parece chegado o momento em que devemos fazer uma reflexão mais aprofundada sobre qual o papel de uma instituição universitária no Século XXI em um país como o Brasil. Mais do que isso: o que deveria se esperado de um pesquisador (cientista social, em específico) contratado para atuar em tempo integral nestas instituições? Os momentos de transição são propícios para avaliações sobre rotas e rumos, mas parece que não temos sido capazes de criar as condições para este tipo de reflexão de tal sorte a deixar mais claro aos nossos alunos, a comunidade acadêmica e a sociedade em geral qual é nossa opinião e percepção.

O contexto atual é de reformar e precisamos nos posicionar com base em argumentos e evidências científicas e não na base da pressão e dos apelos emocionais, que representam perigo.

Tanto agora como no passado, continuo ancorada na ideia de que o essencial é conhecer os processos sociais em seu devir e acreditar na capacidade de agência dos atores sociais de construir sua história e seus destino. A boa sociologia cabe estudar, analisar e criticar estes processos, de forma a produzir conhecimento científico que possa ser útil e orientar a sua prática, assim como servir aos formuladores e gestores de políticas públicas. 


\title{
WAYS OF SOCIOLOGICAL IMAGINATION OR HOW I BECOME A SOCIOLOGIST
}

\begin{abstract}
This article is an essay, almost biographical, about the trajectory of a sociologist, in particular of a professional who started her professional life in the Human Sciences department of the University of Santa Cruz do Sul. The text is structured in several items. Strictly follows a chronological organization that begins with the description of the author's social origin, her choice of social sciences, which the author argues has a profound relationship with her family origin; undergraduate and postgraduate, masters and doctoral degrees and professionalization choices since joining UNISC to this day, as a teacher and researcher at UFRGS. Using strong Weberian influence and why not say, bourdiesan influence, the author connects her career choices with her social background as well as the options she came across on that journey. In the article, the author reflects on the sociological practice of a professional with a pragmatic and applied profile, as well as a description of the topics she researched in her career as a teacher and researcher.
\end{abstract}

Keywords:

Sociology, professional choices, do sociological, academic performance.

\section{REFERÊNCIAS}

BOURDIEU, P. Gostos de classe e estilos de vida. In: ORTIZ, R. (org.). Pierre Bourdieu: Sociologia.São Paulo: Ática, 1983, p. 82-121.

CANO, I. Nas Trincheiras do Método: o ensino da metodologia das Ciências Sociais no Brasil. Sociologias. POA, ano 14, n 31, set-dez 2012, p. 94-119.

DURKHEIM, E. As Regras do Método Sociológico. Cia e Editora Nacional (tradução). SP, 1984.

LONG, N. Sociología del desarrollo: una perspectiva centrada en el actor. Colección Investigaciones. México: Centro de Investigaciones y Estudios Superiores en Antropologia Social, 2007

MILLS, Wright C. A Imaginação Sociológica. Tradução de Waltensir Dutra. Rio de Janeiro. Jorge Zahar Editor, 1975.

THOMPSON, E. P. The Power of Theory and Other Essays. London, Merlyn Press, 1978.

WEBER, M. Economia e sociedade: fundamentos da sociologia compreensiva. Brasília: Ed. da Unb, 1991. 422 p.

\section{Sobre a autora:}

Marília Patta Ramos possui graduação em Licenciatura e Bacharelado Em Ciências Sociais pela Universidade Federal do Rio Grande do Sul, mestrado em Sociologia pela Universidade Federal do Rio Grande do Sul e doutorado em Sociologia - Purdue University. Concluiu seu 
pós-doutoramento no Programa Vilmar Faria (PVF) de Análise Quantitativa em Políticas Públicas no Population Research Center (PRC) da Universidade do Texas. Atualmente é professora associada no departamento de Sociologia da UFRGS. Tem experiência na área de Sociologia, com ênfase em pesquisas quantitativas, atuando principalmente nos seguintes temas: politicas públicas, envelhecimento populacional, sociologia econômica, capital social e desenvolvimento regional. Endereço Eletrônico: mariliaramos68@ gmail.com 